\title{
IMPLEMENTASI SISTEM PAKAR UNTUK MENDIAGNOSA PENYAKIT TULANG PADA MANUSIA MENGGUNAKAN METODE FORWARD CHAINING
}

\author{
Ferly Ardhy \\ Sistem Informasi \\ Stmik Dian Cipta Cendikia Kotabumi \\ Jalan Negara Nomor 03 Candimas Kotabumi Lampung Utara \\ E-mail : ferly@dcc.ac.id
}

\begin{abstract}
Penyakit tulang adalah kondisi yang merusak kerangka dan membuat tulang lemah dan rentan terhadap patah tulang. Tingginya penyakit ini disebabkan ketidaktahuan dan kurangnya pengetahun tentang penyakit tersebut.Oleh karena itu, dibuatlah system pakar untuk mendiagnosa penyakit tulang pada manusia. Metode yang digunakan dalam membuat system pakar ini adalah metode forward chaining dengan menggunakan bahasa pemrograman PHP dan database MySQL. Hasil penelitian ini yaitu aplikasi system pakar untuk mendiagnosa penyakit tulang manusia menggunakan metode forward chaining yang dapat diakses oleh masyarakat secara luas untuk mendiagnosa gejala awal penyakit tulang tanpa terbatas jarak danwaktu digunakan.
\end{abstract}

Kata kunci: SistemPakar, Forward chaining

\begin{abstract}
Bone disease is a condition that damages the skeleton and makes bones weak and vulnerable to fractures. The high disease is caused by ignorance and lack of knowledge about the disease. Therefore, an expert system was created to diagnose bone disease in humans. The method used in making this expert system is the forward chaining method, forward chaining method using the PHP programming language and $M y S Q L$ database. The results of this study are the application of expert systems to diagnose human bone disease using a forward chaining method that can be accessed by the public at large to diagnose early symptoms of bone disease without limited distance and time used.
\end{abstract}

Keywords: Root System, Forward chaining

\section{PENDAHULUAN}

Semakin berkembangnya ilmu pengetahuan dan teknologi sangat pesat dan dapat membuat orang tertarik untuk menciptakan hal-hal yang baru agar dapat berguna dimasa yang akan datang. Sistem pakar adalah perangkat lunak yang didesain khusus berdasarkan artificial intelegence, berfungsi untuk merekam dan menduplikasikan kemampuan pakar. Dengan menggunakan system pakar, pemakaian diajukan beberapa pertanyaan, kemudian pemakai memasukkan jawaban yang ditampilkan dilayar computer sehingga pemakai dapat menemukan rekomendasi atau output yang harus ditempuh pemakai berdasarkan jawaban yang dipilihnya. Pada saat ini system pakar sangat berguna untuk memecahkan masalah yang rumit, mengambil keputusan bahkan berguna untuk mendiagnosa penyakit.

Salah satu penyakit yang banyak dirasakan dimasyarakat adalah penyakit tulang. Penyakit tulang adalah kondisi yang merusak kerangka dan membuat tulang lemah dan rentan terhadap patah tulang. Tingginya penyakit yang menyerang tulang itu sendiri disebabkan keadaan dan perilaku dari masyarakat, seperti stres, kurangnya olahraga, pola makan yang salah. Penyebab lainnya juga karena ketidaktahuan dan kurangnya pengetahuan tentang penyakit tulang itu sendiri. 
Sebenarya penyakit tulang yang dialami seseorang akan lebih mudah diobati jikadilakukan penanganan lebih dini, namun banyak yang tidak tahu tentang gejala penyakit yang mereka rasakan. Informasi tentang gejala dan penanganan penyakit itu bisasanya hanya diketahui dokter. Kita perlu berkonsultasi dengan dokter untuk mengetahui gejala awal, pencegahan, serta penanganannya.Tetapi tidak semua orang dapat berkonsultasi dengan dokter dengan alasan, seperti mahalnya biaya konsultasi kedokter spesialis, jarak rumah sakit yang jauh, dokter ahli yang sedikit dan belum tersebar khususnya di daerah pedesaan, serta tidak punya waktu untuk berkonsultasi ke dokter bagi orang-orang yang memiliki jadwal pekerjaan padat.

Adapun tujuan dan manfaat dari penelitian ini adalah sebagai berikut :

1) Membantu masyarakat memiliki alat pendeteksi awal penyakit tulang dan memberikan saran pengobatan yang mungkin dilakukan, namun aplikasi ini bukan sebagai pengganti dokter tulang (Orthopedi), karena tetap dianjurkan untuk langsung kepada pakarnya.

2) Memberikan pengetahuan kepada masyarakat tentang beberapa penyakit tulang yang biasa diderita masyarakat.

\section{Metodologi Penelitian}

Dalam penelitian ini peneliti menggunakan metode pengumpulan data seperti observasi, wawancara dan uji analisis. Selain itu juga peneliti menggunakan metode fodward chaining sebagai penunjang kepakaran dan metode Extreme Programming (XP)sebagai metode pengembangan system.

\subsection{Sistem Pakar}

Menurut Budi hartono dan Suhartono (2014) :Sistem pakar adalah program komputer yang mensimulasi penilaian dan perilaku manusia atau organisasi yang memiliki pengetahuan dan pengalaman ahli dalam bidang tertentu.

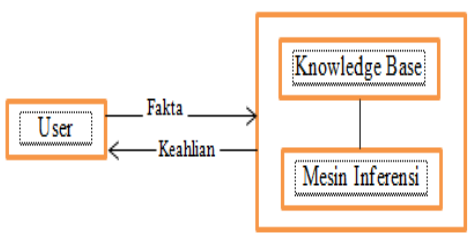

Gambar 1 knowledge based
Gambar 1 menggambarkan konsep dasar suatu system pakar knowledge based. Pengguna menyampaikan fakta atau informasi untuk system pakar dan kemudian menerima saran dari pakar atau jawaban ahlinya. Bagian dalam system pakar terdiri dari dua komponen utamayaitu, knowledge based yang berisi knowledge dan mesin referensi yang menggambarkan kesimpulan. Kesimpulan tersebut merupakan respons dari system pakar atas permintaan pengguna.

\subsection{Forward Chaining}

Forward Chaining menurut Ashari dan Andi (2016) adalah teknik pencarian yang dimulai dengan fakta yang diketahui, kemudian mencocokkan fakta tersebut dengan bagian IF dari rules IF-THEN. Bila ada fakta yang cocok dengan bagian IF, maka rule tersebut dieksekusi. Bila sebuah rule dieksekusi, maka sebuah fakta baru (bagian THEN) ditambahkan ke dalam database. Setiap kali pencocokan, dimulai dari rule teratas. Setiap rule hanya boleh dieksekusi sekali saja. Proses pencocokan berhenti bila tidak adalagi rule yang bisa dieksekusi.

\subsection{Extreme Programming (XP)}

Extreme Programming (XP) merupakan salah satu contoh metodologi pengembangan cepat atau bisa disebut AGILE dalam pengembangan system informasi. (Nina, 2014) XP mempunyai beberapa kelebihan, seperti ringan (lightweight), efesien, beresiko rendah, fleksibel, dan disebut sebagaicara yang menyenangkan dalam pengembangan aplikasi. Sasaran XP adalah tim yang dibentuk berukuran antara kecil sampai medium, tidak perlu menggunakan tim yang besar. XP sangat mengedepankan komunikasi dengan user dalam perancangan program, sehingga sasaran yang dituju dapat diproses secara bertahap dan tapat sasaran.

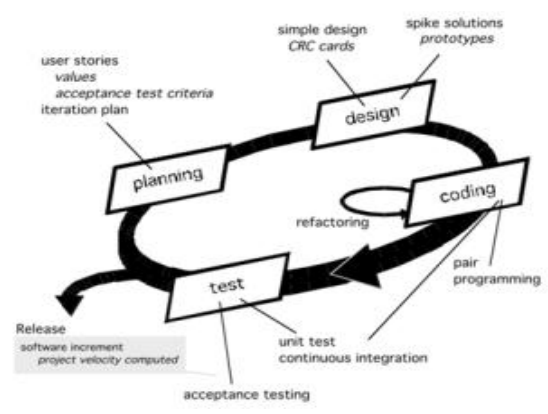

Gambar2 Extreme Programming (XP 


\section{Hasil dan Pembahasan}

\subsection{Hasil}

Pada penelitian kali menghasilkan sebuah desain system dan desain Forward chaining sebagai berikut :

1. Desain system

Desain system meliputi hasil analisa pengolahan data yang di modelkan ke dalam use case system serta class diagram antara lain sebagai berikut :

a. Use case system

use case yang merupakan alur sistem pada sistem pakar diagnosa penyakit tulang, sebagai berikut :
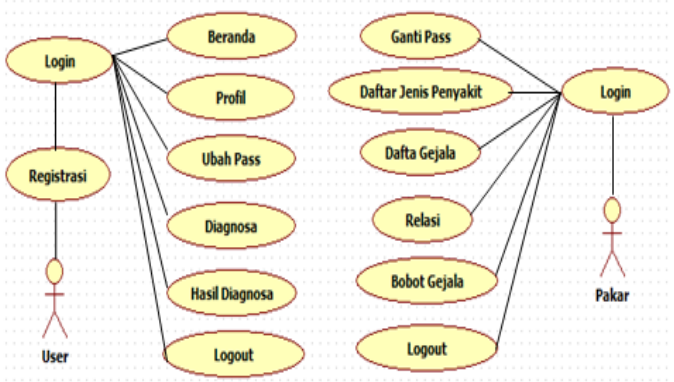

Gambar 3. Use case

b. Class diagram

Class diagram merupakan implementasi hasil desain database yang akan digunakan ke dalam system pakar diagnose penyakit, sebagai berikut:

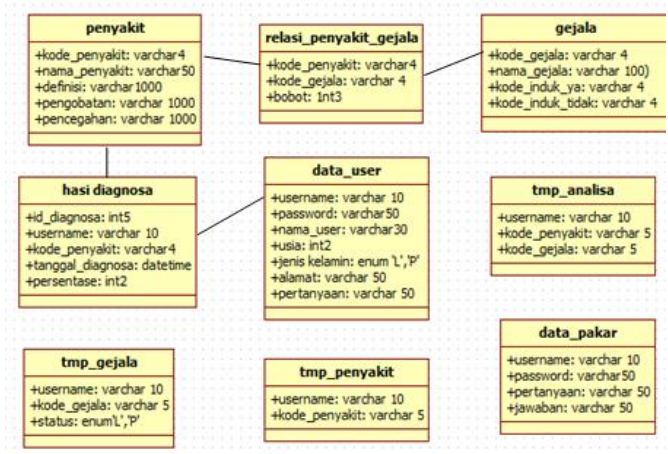

Gambar 4. Class Diagram

2. Desain Rule Forward chaining

Dari beberapa penyakit yang akan diinputkan, telah disusun rule berdasarkan buku dan hasil konsultasi dengan pakar, dalam hal ini adalah dokter. Berikut uraian rule-rule dari sistem pakar untuk mendiagnosa penyakit tulang manusia dengan menggunakan metode forward chaining.

a. Rule 1 (R1) atau Aturan 1

IF G001 (Nyeri pada tulang/sendi), AND G002 (Terasa panas di daerah sakit), AND G003 (terjadi pembengkakan/benjolan didaerah yang terasa panas dan sakit), AND G004 (muncul gejala meradang, berat badan turun, lelah, dan kemampuan beraktivitas menurun), AND G005 (pembengkakan/benjolan makin lama makin besar), AND G006 (ada riwayat pernah jatuh sebelumnya), AND $\quad$ G007 (pembengkakan/benjolan membuat keterbatasan gerak yang menimbulkan sakit), THEN P001 (Osteosarcoma)

b. Rule 2 (R2) atau Aturan 2

IF G001 (Nyeri pada tulang/sendi), AND G008 (Ada benjolan di tulang tulut/paha/tulang lengan atas), AND G009 (Benjolan terasa keras dan tidak nyeri), AND G010 (Nyeri pada benjolannya ketika kelelahan), THEN P002 (Osteochondroma)

c. Rule 3 (R3) atau Aturan 3

IF G001 (Nyeri pada tulang/sendi), G011 (Sendi berwarna kemerahan), AND G012 (Mengalami pembengkakan), AND G013 (Mengalami demam), AND G014 (Nyeri jika dipegang / diraba (terasa senut-senut)), AND G015 (Ada riwayat infeksi / luka sebelumnya), AND G016 (Pada bagian yang sakit berair (bernanah, bau busuk)), THEN P003 (Osteomylitis)

d. Rule 4 (R4) atau Aturan 4

IF G001 (Nyeri pada tulang/sendi), G017 (Adanya kecenderungan tinggi badan berkurang), AND G018 (Mengalami menopause), AND G019 (Postur tubuh memendek / membungkuk), AND G020 (Nyeri pada pergelangan tangan dan pangkal paha), AND G021 (Nyeri di tulang belakang / punggung), AND G023 (Nyeri lengan sampai tangan bahkan kesemutan jarijemari), THEN P004 (Osteoporosis)

e. Rule 5 (R5) atau Aturan 5

IF G001 (Nyeri pada tulang/sendi), G024 (Adanya nyeri dan rasa sakit pada tulang leher), AND G025 (Rasa terbakar di leher, terutama pada malam hari), AND G026 (Nyeri menjalar sekitar telinga dan mata), 
AND G027 (Nyeri kepala kadang di sertai migraine dan vertigo), AND G028 (Nyeri puncak bahu terasa mencengkeram kadang sampai ke dada), AND G029 (Nyeri terasa seperti sengatan listrik di tangan dan kaki), THEN P005 (Spondylosis Cervical (Nyeri Tulang Leher))

f. Rule 6 (R6) atau Aturan 6

IF G001 (Nyeri pada tulang/sendi), AND G022 (Nyeri pada punggung bagian bawah (pinggang)), AND G030 (Nyeri hebat pada punggung bagian bawah (pinggang) setelah membungkuk / mengangkat), AND G031 (Nyeri pada waktu duduk lama), AND G032 (Nyeri jika berjalan dan berdiri), AND G033 (Nyeri menjalar sampai ke bagian paha, lutut, betis, dan telapak kaki), AND G034 (Kaki sering kesemutan), AND G035 (Riwayat pernah jatuh terduduk), THEN P006 (Low Back Pain (Nyeri Punggung Bawah))

g. Rule 7 (R7) atau Aturan 7 IF G001 (Nyeri pada tulang/sendi), AND G036 (Nyeri yang menjalar di daerah pinggang dan paha), AND G037 (Mengalami kelemahan otot sehingga sulit untuk berjalan, membawa, meraih sesuatu, atau berpegangan), AND G038 (Mengalami pembengkokan pada tulang (bentuk $\mathrm{O}$ dan X)), AND G039 (Mati rasa di sekitar mulut), THEN P007 (Osteomalacia)

h. Rule 8 (R8) atau Aturan 8

IF G001 (Nyeri pada tulang/sendi), G040 (Pemakaian sendi berlebihan dan hilang dengan istirahat), AND G041 (Nyeri malam hari dan kekakuan sendi pada pagi hari), AND G042 (mudah letih dan lemas, THEN P008 (Osteoartritis)

Dari uraian rule-rule diatas dapat dipersingkat informasinya menjadi tabel keputusan yang dapat dilihat pada tabel berikut

\section{Tabel 1 Rule-Rule}

\begin{tabular}{|c|c|c|}
\hline Rule & If & Then \\
\hline R1 & $\begin{array}{c}\text { G001, G002, G003, G004, G005, } \\
\text { G006, G007 }\end{array}$ & P001 \\
\hline R2 & G001, G008, G009, G010 & P002 \\
\hline R3 & $\begin{array}{r}\text { G001, G011, G012, G013, G014, } \\
\text { G015, G016 }\end{array}$ & P003 \\
\hline R4 & $\begin{array}{r}\text { G001, G017, G018, G019, G020, } \\
\text { G021, G023, G024 }\end{array}$ & P004 \\
\hline
\end{tabular}

\begin{tabular}{|c|c|c|}
\hline R5 & $\begin{array}{r}\text { G001, G025, G026, G027, G028, } \\
\text { G029 }\end{array}$ & P005 \\
\hline R6 & $\begin{array}{r}\text { G001, G022, G030, G031, G032, } \\
\text { G033, G034, G035 }\end{array}$ & P006 \\
\hline R7 & G001, G036, G037, G038, G039 & P007 \\
\hline R8 & G001, G040, G041, G042 & P008 \\
\hline
\end{tabular}

\subsection{Pembahasan}

\subsection{Halaman Utama}

Saat pengunjung dan admin mengakses website maka akan muncul halaman utama seperti gambar dibawah ini.

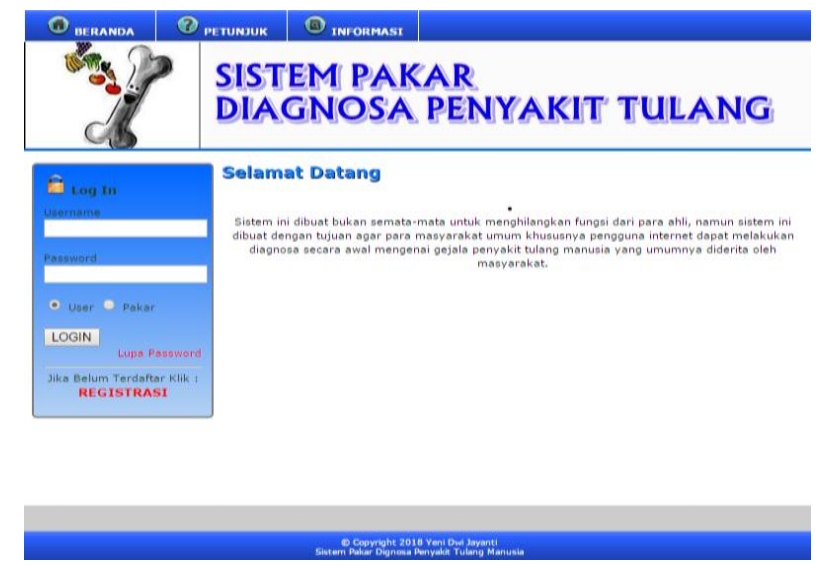

\section{Gambar 5. Halaman Utama}

\subsubsection{Halaman Registrasi User}

Sebelum melakukan konsultasi ke sistem, user/pengunjung harus melakukan login menggunakan username dan password. Apabila user belum memiliki username dan password maka harus melakukan registrasi terlebih dahulu seperti yang ditunjukkan pada halaman panduan. Dengan mengklik Registrasi, maka form registrasi pun akan muncul seperti gambar dibawah ini.

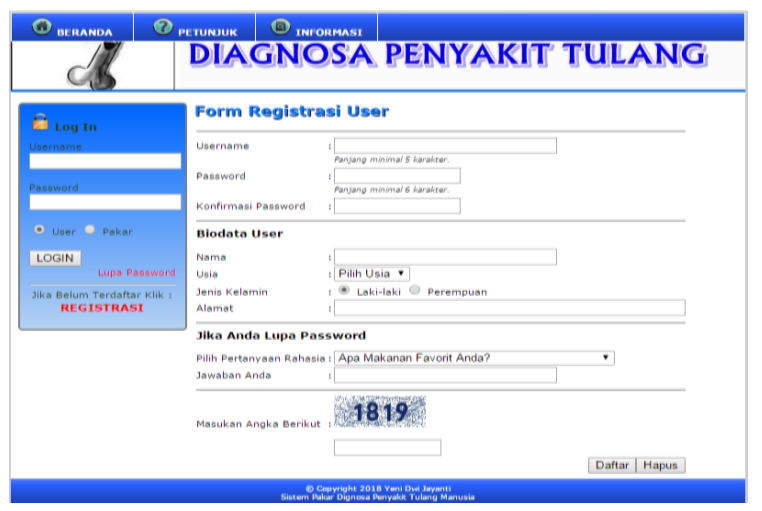

Gambar 6 Regristrasi User 


\subsubsection{Halaman Diagnosa dan hasil diagnosa} Halaman berikutnya yaitu halaman diagnosa. Halaman ini dapat diakses apabila user telah melakukan registrasi dan login sebelumnya. Setelah berhasil login, maka user dapat memilih menu diagnosa yang terletak dibagian atas halaman website seperti gambar berikut.

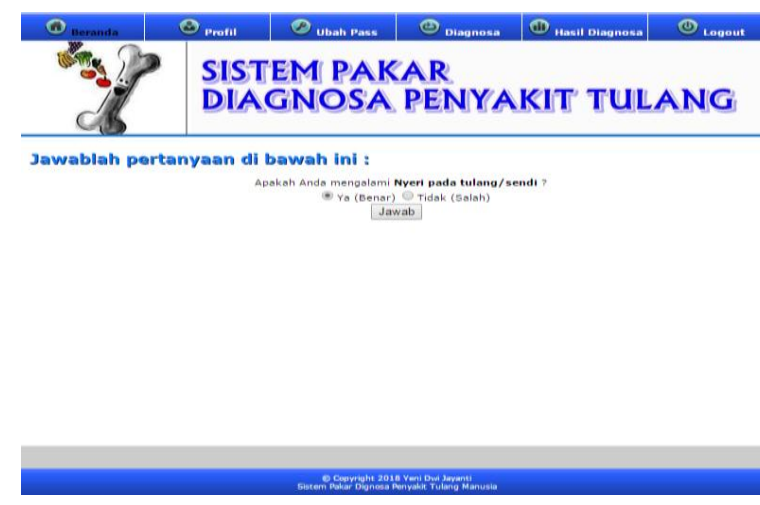

GAmbar 6. Halaman Diagnosa

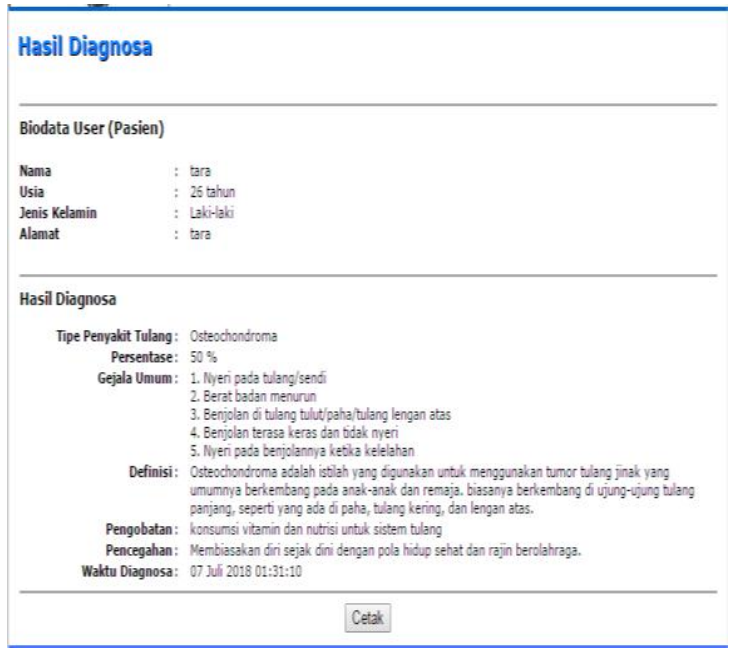

Gambar 7. Hasil Diagnosa

\section{Kesimpulan \\ 4.1 Kesimpulan}

Setelah menyelesaikan penelitian ini, penulis menarik beberapa kesimpulan sebagai berikut:

1. Pembuatan aplikasi dengan konsep sistem pakar yang menggunakan interface web dalam pendiagnosaan penyakit kulit dapat membantu pendiagnosaan awal penyakit yang berkaitan dengan kulit.

2. Aplikasi sistem pakar ini dirancang beserta keluarannya yaitu berupa diagnosa beserta penanganan dan pengobatan dari penyakit kulit.
3. Dengan adanya aplikasi sistem pakar ini dapat menjadi database pengetahuan mengenai hal-hal yang berhubungan dengan gejala dan diagnosa penyakit-penyakit kulit beserta solusi dan diagnosanya.

\section{PUSTAKA}

[1] Ashari dan Andi Yulia Muniar. 2016. "Penerapan Sistem Pakar untuk Mendiagnosa Penyakit Pencernaan dengan Pengobatan Bahan Alami”. Seminar Nasional Sains dan Teknologi, Fakultas Teknik Universitas Muhammadiyah Jakarta. P-ISSN : 2407-1846, e-ISSN : 2460-8416.

[2] Budiharto, W. dan Suhartono, D. (2014), ARTIFICIAL INTELLLIGENCE Konsep dan Penerapanya. Andi Offset, Yogyakarta.

[3] Nina Rahayu. 2014. “ Perancangan Executive Informasi System (EIS) Dalam Bidang Penjualan pada Karinda Cafe dan Resto". Laporan Skripsi, AMIK Raharja, Tangerang.

[4] Rahmi Ras Fanny, dkk. 2017. "Perancangan Sistem Pakar Diagnosa Penyakit Asidosis Tubulus Renalis Menggunakan Metode Certainly Factor dengan Penelusuran Forward Chaining". Jurnal Media Informatika Budidarma, Vol 1, No 1, ISSN 25488368 (Media Online), Hal: 13-16. 
